\title{
New Inorganic Ion-exchange Material for the Selective Removal of Fluoride from Potable Water Using Ion-selective Electrode
}

\author{
Rasheed M.A.Q. Jamhour \\ Department of Applied and Basic Science, Tafila Applied University College \\ P.O. Box 179, Al-Balqa' Applied University, Tafila, Jordan
}

\begin{abstract}
An ion-exchange procedure involving the selective retention of fluoride ions from aqueous solutions containing $1,5,10,20$ and $50 \mathrm{mg} \mathrm{F}^{-} \mathrm{L}^{1}$ using a new inorganic ion exchanger zirconium(IV) oxide-ethanolamine $\mathrm{ZrO}$-EA and its application to fluoride removal from potable water has been described. A column equilibrium studies, batch process and different analytical parameters such as concentration, $\mathrm{pH}$ and temperature for the quantitative recoveries of $\mathrm{F}$ ion using $\mathrm{ZrO}-\mathrm{EA}$ exchanger were investigated and determined by an ion selective electrode. The effect of some other anions that might be present with the analyte was also examined. The column experiments showed a quantitative collection of fluoride at low concentration in water samples with more than $96 \%$ recovery.
\end{abstract}

Key words: Fluoride Removal, Inorganic Ion Exchange, Drinking Water, Zirconium Oxideethanolamine

\section{INTRODUCTION}

Determination of fluoride in drinking water has received a considerable attention, due to its beneficial and detrimental effects on health. The fact that problems associated with the excess fluoride in drinking water is highly endemic and widespread in countries that depend mainly on groundwater. Since, fluoride can result from the natural dissolution of minerals of the earth crust, then leaches to groundwater and when the maximum levels exceed $1.5 \mathrm{mg} \mathrm{L}^{1}$ in drinking water it is known to cause serious health problems [1-5]. Fluoride ingested with water, goes on accumulating in bones up to age of 55 years. At higher doses fluoride can interfere with carbohydrates, lipid protein, vitamin, enzyme and mineral metabolism [6]. Therefore, pre-concentration or removal of fluoride from aqueous solutions is a matter of great concern in analytical and environmental works. This prompted researchers to explore and develop number of new analytical methods as well as organic and inorganic materials adopting various processes for the selective removal or lowering the maximum contaminate level of fluoride in water. A number of methods have been reported for the removal of fluoride from water [7-11]. A combine cake alum and a polymeric anionic flocculent material has been developed [12]. Column packed with fly ash was also reported to fluoride uptake from wastewater [13]. Many inorganic adsorbents/ion exchangers were also reported [14,15]. Namely, hydrous cerium oxide powder or polyolefinic resin beads, which reduces fluoride ion concentration to $<1$ $\mathrm{mg} \mathrm{L}^{1}$ in wastewater [16], activated alumina reported to collect low-level fluoride in natural waters by column method [17] and hydrous zirconium oxide used for the removal of fluoride from aqueous solutions [18]. The aim of this research was to evaluate the removal of fluoride ions from groundwater and drinking water by studying the sorption behavior of fluoride on an inorganic ion exchanger i,e., zirconium(IV) oxideethanolamine $\mathrm{ZrO}-\mathrm{EA}$ at different conditions in combination with the determination using ion selective electrode. A comparison has also been made for the sorption of fluoride ion on ZrO-EA to that obtained on an anion exchange resin Amberlite IR-400 in $\mathrm{Cl}^{-}$form.

\section{MATERIALS AND METHODS}

Reagents and Apparatus: Zirconium oxychloride octahydrate (CDH, India) and ethanolamine (E. Merck) were used for the synthesis of ion exchange material. Standard solution of fluoride was prepared from weighed sodium fluoride and stored in polyethylene bottle. TISAB buffer solution was prepared by dissolving $58 \mathrm{~g}$ of sodium chloride, $4 \mathrm{~g}$ of 1,2diaminocyclohexane tetra acetic acid (CDTA) and 57 $\mathrm{mL}$ of glacial acetic acid in water and diluting to 500 $\mathrm{mL}$. After placing in a cold water bath, $5 \mathrm{M}$ sodium hydroxide was slowly added with stirring until the $\mathrm{pH}$ lies in the range 5.0-5.5 and diluted to $1 \mathrm{~L}$.

Toshniwal single electrode $\mathrm{pH}$ meter and Ion-Analyzer with fluoride ion-selective electrode (Consort, Belgium) were used for $\mathrm{pH}$ measurements and fluoride ion concentration respectively. Calibration was achieved in the range $0.1-10 \mathrm{ppm} \mathrm{F}$, by using known concentration of sodium fluoride standards.

Synthesis of the Ion-exchange Material: Zirconium(IV) oxide-ethanolamine exchanger was 
prepared by mixing $0.2 \mathrm{M}$ aqueous solution of ethanolamine with a $0.1 \mathrm{M}$ zirconium oxychloride solution in the ratio of $1: 1(\mathrm{v} / \mathrm{v})$ at $\mathrm{pH}$ 3.The desired $\mathrm{pH}$ was adjusted by adding dilute hydrochloric acid dropwise. The white gel so obtained was allowed to stand overnight at room temperature and then filtered, washed with demineralised water to remove excess reagents and till the filtrate attains a $\mathrm{pH}$ value of 5 or 6 , then dried at $40^{\circ} \mathrm{C}$. The material broke into small shining granules when immersed in water. The formula of ZrO-EA exchanger is given in Fig. 1. Detailed synthetic procedure for this material was given in previous study [19]. The exchanger was then converted into $\mathrm{H}^{+}$form by treating it with $1.0 \mathrm{M} \mathrm{HNO}_{3}$ for $24 \mathrm{~h}$ with occasional shaking. The $\mathrm{H}^{+}$form exchanger was further converted into $\mathrm{Ca}^{2+}$ form by treating it with calcium solution.

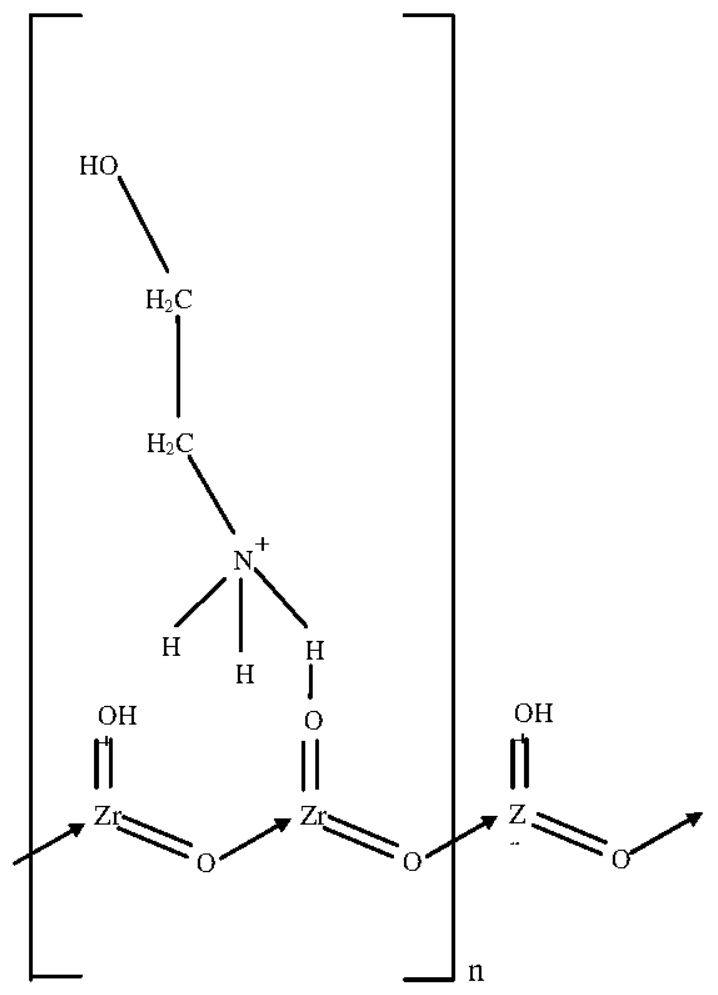

Fig. 1:Structure of Now Ion-exchanger ZrO-EA

Column Preparation and Ion Exchange Procedure: The glass column containing a stopcock and a porous disk at the bottom with glass wool support, was $25 \mathrm{~cm}$ long and $1.0 \mathrm{~cm}$ in diameter. Then, $1.0 \mathrm{~g}$ of $\mathrm{ZrO}-\mathrm{EA}$ exchanger was packed into the column. It was washed successively with water, acetone, respectively. The sample solutions of varying concentration were adjusted to $\mathrm{pH} 2$ and passed through the column at a flow rate of 1-2 $\mathrm{mL} \mathrm{min}^{1}$. After passing of this solution, the column was rinsed twice with water. The adsorbed fluoride on the column was eluted with $1.0 \mathrm{M}$
$\mathrm{HCl}$ solution then analyzed for fluoride concentration by ion selective electrode.

Sample Preparation and Sorption Procedure: In order to study the adsorptive capacity of $\mathrm{ZrO}$-EA exchanger in $\mathrm{Ca}^{2+}$ form, the batch method was used. To $0.5 \mathrm{~g}$ exchanger was added $50 \mathrm{~mL}$ of aqueous solution containing fluoride ion at various concentration $(0.1$ to $20 \mathrm{mg}$ ) in a $100 \mathrm{~mL}$ polyethylene flask was shaken in a thermostat water bath at $20,30,40$ and $50^{\circ} \mathrm{C}$ for $6 \mathrm{~h}$. The ion exchanger was then removed by filtration. The concentration of the analyte ion in the filtrate was determined using ion selective electrode and from this value the sorption capacity (mmol/g dry exchanger) and percent uptake for the sorption of fluoride ion was calculated by the following equation:

Percent uptake $(\mathrm{U} \%)=$ conc. of Fin the exchanger phase/ initial conc. of $\mathrm{F}^{-}$in water * 100 .

Analysis of Water Samples: The groundwater and drinking water samples were collected in clean prewashed polyethylene bottles. Filtered, then acidified to $1 \%$ with nitric acid and stored in one letter polyethylene bottles at $4^{\circ} \mathrm{C}$ [20]. A sample of this water was taken and the above separation/ion exchange procedure was applied. The investigated fluoride ions in the final solutions were then determined by ion selective electrode.

\section{RESULTS AND DISCUSSION}

The sorption capacities of ZrO-EA exchanger in $\mathrm{Ca}^{2+}$ form for fluoride ion in batch process at $30^{\circ} \mathrm{C}$ are 0.82 , $0.75,0.58,0.54$ and $0.40 \mathrm{mmol} \mathrm{g}^{1}$ dry exchanger at $\mathrm{pH}$ $2,3,4,5$ and 6 , respectively. The sorption capacity decreases regularly with increasing $\mathrm{pH}$ that indicates the stability of $\mathrm{CaF}^{+}$ion at low $\mathrm{pH}$ value. The exchange material in $\mathrm{Ca}^{2+}$ form has been taken for further studies in acidic media due to its higher selectivity towards fluoride ions. The volume of the buffer solution had no much influence on sorption.

It is observed that a temperature of $30^{\circ} \mathrm{C}$ is optimum temperature for maximum uptake (Table 1). The exchanger shows a decreasing trend above and below this temperature. The expected capacity trend, which was reported to be better at high temperature [21], is altered. Again this order of uptake is $\mathrm{pH}$ dependent and it decreases with increasing $\mathrm{pH}$ values of solutions. For comparison, results of similar measurements on Amberlite IR-400 in $\mathrm{Cl}^{-}$form which are shown in Table 2 indicate the same findings of uptake with a much lower affinity toward fluoride ion to that of $\mathrm{ZrO}-\mathrm{EA}$ exchanger in $\mathrm{Ca}^{2+}$ form. When the effect of concentration is studied at $30^{\circ} \mathrm{C}$, the exchanger in $\mathrm{Ca}^{2+}$ form exhibits strong sorption ability, particularly in low concentration region. This may be attributed to small particle size with large surface area, where a chemical reaction is more favorable and stable. The small size of 
Table 1: Percent Uptake of $\mathrm{F}^{-}$Ion on ZrO-EA at Different $\mathrm{pH}$ Values and Temperatures

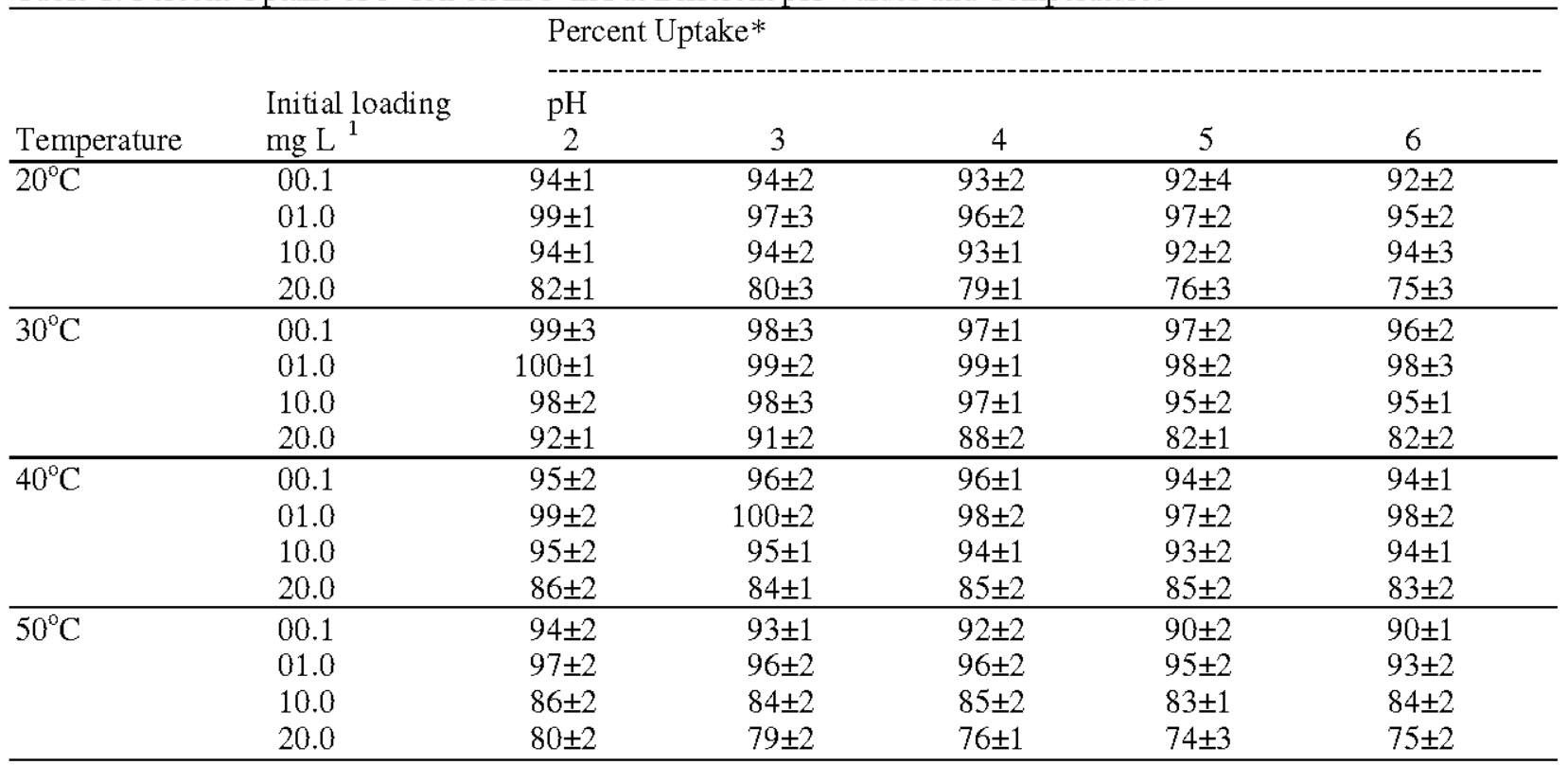

*Average of three determinations.

Table 2: Percent Uptake of $\mathrm{F}$ Ion on Amberlite IR- $400 \mathrm{in} \mathrm{Cl}$ form at Different $\mathrm{pH}$ Values (Temperature: $30^{\circ} \mathrm{C}$ )

\begin{tabular}{|c|c|c|c|c|c|}
\hline \multirow[t]{2}{*}{ Initial loading $\mathrm{mg} \mathrm{L}^{1}$} & \multicolumn{5}{|c|}{ Percent Uptake* } \\
\hline & \multicolumn{5}{|l|}{$\mathrm{pH}$} \\
\hline & 2 & 3 & 4 & 5 & 6 \\
\hline$\overline{0.1}$ & $99 \pm 2$ & $98 \pm 2$ & $98 \pm 2$ & $99 \pm 1$ & $98 \pm 2$ \\
\hline 1.0 & $96 \pm 2$ & $96 \pm 2$ & $94 \pm 1$ & $94 \pm 2$ & $94 \pm 2$ \\
\hline 10 & $78 \pm 2$ & $75 \pm 1$ & $72 \pm 2$ & $68 \pm 2$ & $62 \pm 2$ \\
\hline 20 & $65 \pm 2$ & $62 \pm 2$ & $58 \pm 3$ & $55 \pm 2$ & $46 \pm 2$ \\
\hline
\end{tabular}

*Average of three determinations.

Table 3: Effect of Ammonium Salts (anions) on the Sorption of F on ZrO-EA

\begin{tabular}{lccc}
\hline Anion (added as ammonium salt) & Concentration $\left(\mathrm{mg} \mathrm{L}^{1}\right)$ & Concentration in the eluent $\left(\mathrm{mg} \mathrm{L}^{1}\right)$ & Recovery $(\%)^{*}$ \\
\hline $\mathrm{Cl}^{-}\left(\mathrm{NH}_{4} \mathrm{Cl}\right)$ & 1000 & 24.0 & $101 \pm 3$ \\
& 500 & 7.0 & $99 \pm 2$ \\
& 100 & - & $99 \pm 2$ \\
$\mathrm{SO}_{4}{ }^{2-}\left(\left(\mathrm{NH}_{4}\right)_{2} \mathrm{SO}_{4}\right)$ & 500 & 12 & $97 \pm 2$ \\
& 250 & 5.0 & $98 \pm 1$ \\
& 100 & - & $99 \pm 2$ \\
\hline
\end{tabular}

*Average of four determinations at $30^{\circ} \mathrm{C}$.

Table 4: Recovery of F Ion from Water Samples

\begin{tabular}{|c|c|c|}
\hline \multirow[b]{2}{*}{$\begin{array}{l}\text { Amount added } \\
\left(\mathrm{mgL}^{1}\right)\end{array}$} & \multicolumn{2}{|c|}{ Water Samples From Tafila City } \\
\hline & $\begin{array}{l}\text { Found } \\
\left(\mathrm{mg} \mathrm{L}^{1}\right)\end{array}$ & $\begin{array}{l}\text { Recovery } \\
(\%)\end{array}$ \\
\hline$\overline{0}$ & 0.8 & - \\
\hline 1.0 & $1.8 \pm 0.2$ & $99 \pm 1$ \\
\hline 0 & 0.8 & - \\
\hline 5.0 & $6.1 \pm 0.3$ & $98 \pm 2$ \\
\hline 0 & 1.2 & - \\
\hline 10 & $11.4 \pm 0.5$ & $98 \pm 1$ \\
\hline 0 & 1.2 & - \\
\hline 20 & $21.5 \pm 0.2$ & $97 \pm 2$ \\
\hline 0 & 0.8 & - \\
\hline 50 & $51.3 \pm 0.9$ & $97 \pm 3$ \\
\hline
\end{tabular}

the fluorine atom causes it to be saturated quickly with electron density on the surface of zirconium oxide and ethanolamine. Furthermore, the great electronegativity of fluorine combined with its small size results in a much greater reactivity. The reaction mechanism is supposed to be intraparticle diffusion control. This fact is conformed by showing no effect of the presence of other anions or ammonium salts. Table 3 shows the results of the effect of some anions like $\mathrm{SO}_{4}^{-2}$ and $\mathrm{Cl}^{-}$ that might be present in potable water samples. The column method described in the experimental part was followed to evaluate the possibility of selective recovery. The concentration of these salts were found 
significantly low in the eluent solutions giving a suitable determination and potential application to water samples. In addition, the presence of ammonium salt, which in homogeneous medium, found profound effect towards the stability of $\mathrm{CaF}_{2}$ [22].

In order to estimate the accuracy of the method and to achieve practical applications, different amounts of fluoride ions $1,5,10,20$ and $50 \mathrm{mg} \mathrm{F}^{-}$were added to $500 \mathrm{~mL}$ of drinking water samples collected from Tafila city. The procedure in experimental section was followed. Table 4 shows a very good agreement between the added and measured fluoride amounts. The recovery values were higher than $96 \%$, which confirm the accuracy of the proposed procedure and the effectiveness of $\mathrm{ZrO}-\mathrm{EA}$ exchanger in $\mathrm{Ca}^{2+}$ - form to remove fluoride from drinking water and is also superior to Amberlite IR-400 resin in $\mathrm{Cl}^{-}$-form.

\section{CONCLUSION}

Based on these data obtained in this study, it can be concluded that ZrO-EA exchanger is an effective material for water treatment that comply with the maximum contaminate level for fluoride ion in drinking water. Further work will be focused on the use of this material to remove fluoride ions from wastewater.

\section{REFERENCES}

1. Kowalski, F., 1999. Fluoridation. J. AWWA., 91: 4-13.

2. Saxena, V.K. and S. Ahmed, 2001. Dissolution of fluoride in groundwater: A water-rock interaction study. Environ. Geol., 40: 1084-7.

3. Srivastara, S.K., R.K. Gupta and J.S. Bhargar, 2000. Dissolution of high fluoride in groundwater of Puri District, Orissa. Pollut. Res., 19: 279-84.

4. Diesendrof, M., J. Colquhoun and B. Spittle, 1998. Fluoridation and bones: Author's response to critics. Fluoride 31: 166-9.

5. Jain, C.K., M.K. Sharma, K.K.S. Bhatia and S.M. Seth, 2000. Groundwater pollutionendemic of fluorosis. Pollut. Res., 19: 505-9.

6. Nagendra, Rao C.R., 2003. Proceedings of the Third International Conference on Environ. and Health. Chennai, India, pp: 386-399, 1517 Dec.

7. Wen, M.L., Q.C. Li and C.Y. Wang, 1996. Developments in the analysis of fluoride $1993-$ 1995. Fluoride, 29: 82-88.

8. Wen, M.L., N.H. Shi, Y. Qin and C.Y. Wang, 1998. Developments in the analysis of fluoride 1995-1997. Fluoride, 31: 74-80.

9. Papaefstathiou, I., M.T. Tema and M.D. Luque de Castro, 1995. On-line evaporation separation process for the potentiometric determination of fluoride in "dirty" samples. Anal. Chim. Acta, 308: 246-252.
10. Corbilon, M.S., M.P. Carril and J.M. Madariaga et al., 1995. Fast determination of total fluoride by direct potentiometry in samples of aluminum fluoride and cryolite. Analyst, 120: 2227-2231.

11. Hara, H. and C.C. Huang, 1997. Buffer composition suitable for determining very low fluoride using a fluoride ion-selective electrode and its application to the continuous analysis of rain water. Anal. Chim. Acta, 338: 141-147.

12. Pinon-Miramontes, M., R.G. BautistaMargulis and A. Perez-Hernandez, 2003. Removal of arsenic and fluoride from drinking water with cake alum and a polymeric anionic flocculent. Fluoride, 36: 122-128.

13. Piekos, R. and S. Paslawska, 1999. Fluoride uptake characteristics of flyash. Fluoride, 32: 14-19.

14. Zevenbergen, C., L.P. vanReeuwijk, G. Frapporti, R.J. Louws and R.D. Schuiling, 1997. A simple method for defluoridation of water at village level by adsorption on Ando soil in Kenya. Fluoride, 30: 128-133.

15. Agarwal, M., K. Rai, S. Srivastava, M.M. Srivastava, S. Prakash, R. Srivastav and S. Dass, 1998. Fluoride sorption on clay and clay minerals: An attempt to search for viable defluoridating agent. Fluoride, 31: 155-9.

16. Nomura, J., H. Imai and T Miyake, 1989. Emerging technologies in waste management. ACS Symp. Ser. (Pub. 1990) 422: 157.

17. Wu, J.C. and A. Nitya, 1979. Water defluorination with activated alumina. J. Environ. Eng., ACSE, 105: 357-367.

18. Yamabe, K., S. Kudo, Y. Nawata and A. Jyo, 2003. Column-mode removal of fluoride by zirconium(IV) loaded methylenephosphonate resin. Third Intl. Conference on Ion exchange ICIE'03, July 14-18.

19. Qureshi, S.Z., R.M.A.Q. Jamhour and N. Rahman, 1996. Surface interaction of ethanolamine with hydrous zirconium(IV) oxide gel: Characterization and separation of some anionic species by column chromatography. Ann. Chim., Fr., 21: 609619.

20. Soylak, M. and M. Doggan, 1995. Physical and chemical properties of the mineral spring waters from central region of Anatolia. Fresen. Envir. Bull., 4: 35-40.

21. Venkateswarlu, P. and N. Rao, 1953. Removal of fluorides from water by Magnesia. Indian Med. Lab., 41: 475-9.

22. Greenwood, N.N. and A. Earnshow, 1984. Chemistry of Elements. John Wiley and Sons Inc., pp: 129-131. 